\title{
HOW TO MAKE THE TEACHING OF SCIENCE ATTRACTIVE?
}

\author{
Maher Abboud*
}

The important scientific and technological advances occurring at the dawn of the twenty-first century offer potentials and limitations.

They offer a potential for improved health services, environmental quality, educational opportunities, consumer products, communication systems and in general a better quality life. This potential is actuated, however, only if there is an equitable distribution of resources and an equal opportunity for all to participate in knowledge production. Herein materialize the limitotions and the challenges: how do we assure equal opportunities for participation and just resource distribution?

Some authors of the Arab Human Development Report 2003 argue that reforming the outdated and under resourced education systems is not only necessary but very urgent if we are to participate in knowledge production and become part of the "global Knowledge stream". Educational reform is also necessary in order to benefit from the tremendous opportunities offered by science and technology. Moreover, the report suggests that for change to be successful its processes have to be home grown. That is, change and advancement will be possible when the change process originates from within each individual and country. Science and technology by

\footnotetext{
* Mâtre de conférences, Professeur de chimie, Directeur du département de chimie, Faculté des sciences, Universite Saint-Joseph, Beyrouth, LIBAN

Campus des Sciences et Technologies Mor Roukos, Mkallès B.P. 11-0514 \&: 0096145326611 2/3 fax : 00961 4-532657 e-mail : maher.abboud@fs.usj.edu.lb
} 
themselves do not help individuals and nations to advance. It is the serious effort and determination that is exerted by individuals and countries to understand the possibilities offered by science and technology and to realize the importance of producing, rather than only using, science and technology that initiate advancement. In addition, the values placed on education, science and technology and their methods are important driving forces behind any important advancement. Memorizing terms, and even whole science books is useless if the methods and values of science and technology as well as their limitations are not cherished.

Students graduating from schools and universities at the beginning of the twenty first century need to be equipped with significant scientific and technological knowledge and science process skills to enable them to be productive members of society. Likewise, the need to develop attitudes that will motivate them to deal with their erroneous concepts and use their knowledge and skills in a responsible manner in solving science related problems. Specially, they must develop a thorough knowledge of central concepts that they can apply in a variety of situations and science process and thinking skills that are especially important for effective functioning in the world of work.

For example, they must learn to identify and analyze problems and to explore and test solutions in a variety of situations. This strong conceptual base and these essential skills should be at the heart of teaching and learning science and technology at all educational levels, especially at the secondary and university levels.

\section{Some Recommendations}

1. Research in cognitive psychology and education suggests that students at all levels need to have the opportunity to learn science actively by working in collaboration with peers and teachers. Consequently, some authors argue that today's students are qualitatively different from their teachers, hence they need to change their methods and beliefs about teaching. They need to realize that teaching is not disseminating information but rather helping students develop deep understandings of the methods, habits of mind, and content of science. This change requires that university faculty members are educated in new teaching approaches and be provided with the necessary resources to implement these approaches in the classroom. Traditionally teacher education was relegated to pre-college teaching. It is time now to extend this education into universities because the needs of students are the same at all educational levels. Reforming secondary schools and university education should proceed in parallel because of the intimate and reflexive relations between the two stages. This increasing emphasis on teaching should receive equal attention in the reward systems of universities if it is to be successful. 
2. Associated with the changes in instruction are necessary changes in assessment and evaluation systems. The nature of tasks students perform in a studentcentered learning environment requires different methods of assessment and evaluation. Teachers at all levels need to be schooled in these methods.

3. Students at the secondary and university levels need to be involved in extended research projects with faculty mentors if they are to be schooled in the methods and habits of mind associated with science. This requires that both students and faculty members endeavor to become "science natives". If this is not done, our students will continue being consumers of information who are standing on the sidelines while the world moves forward at an exceedingly remarkable pace.

4. Secondary level and university students may need to survey fewer science topics in more depth. This should provide them with opportunities to focus on the methods and content of science rather than just on the content. This in no way is a call to minimize the importance of scientific content. The real challenge for all teachers, is to integrate rigor of content with high-level thinking and active use of knowledge in an effort based environment that rewards authentic and high quality accomplishments.

5. The purpose of science education should be debated among all stakeholders. in an increasingly science dependent world the purpose of science education cannot be merely to prepare students for higher grades and for science and science related careers. A small minority of today's students choose science related careers. The challenge is to design science curricula that prepare all students to function properly in the world of the $21^{\text {st }}$ Century. Thus, all students need to become scientifically literate, able to understand the role of evidence, the epistemological basis of science learning, the relationships between scientific and social issues, and the values inherent in doing science.

6. It goes without saying that students and teachers at all educational levels need to be technologically literate. More importantly, teachers need to work hard on understanding the demands of a digital world in which their students grew up. This world qualitatively very different from the world they grew in and they need to invest the time and effort necessary to reap the huge potentials to improve education that are inherent in this new world.

7. Most educational research at the present time is focused on investigating issues and problems related to pre-college education. Educational and assessment practices used at the college levels should attract attention. Moreover, university reward systems should change to accommodate this new type of research if it is to flourish. 


\section{A. What are the Future Challenges in education?}

Science Education is facing four major challenges: fluidity of work place, escalation of knowledge, unpredictable future, and "marketization" of educational services.

\section{Fluidity of workplace}

There was a time when planning for the workplace was a straightforward exercise: manpower planners would map out needs of the different sectors of the economy with reasonable precision, classify corresponding jobs by level, define skill requirements for each job and subsequently project the manpower needs. It was then fairly easy for educational planners to take this "dependable "information and build on it science and technology education programs.

Life is not that easy anymore. Everything is changing faster than the life cycle of a training program: sectorial needs, job definitions, skill requirements and training standards. Countries, firms and workers are all feeling the effects of the changing patterns of trade and competition, technological innovation and globalization of information.

First, producers of tradable goods and services now must operate in a global marketplace. They will be more interdependent, more susceptible to external economic shocks, and more vulnerable to international changes in demand for types and quality of products and services. It also makes it hard to predict the skills that will be needed in the future.

Second, the production of manufacturing and high-valued services no longer filter down "naturally" from high-income to middle - and low-income countries based on labor costs alone. The location of manufacturing and high-value service depends on the producer's ability to control quality, and manage flexible, informationbased systems.

Third, the emerging economy will no longer be centrally created and controlled. As countries become more open to international trade, production will reflect international and not just national demand. This environment will place a premium on entrepreneurship, or the ability of individuals and institutions to respond to market changes through evolving their own businesses or creating new ones.

\section{il. Escalation of Knowledge}

The workplace, and society in general are becoming more knowledge and technology based. Generation, selection, assimilation, and application of scientific and 
technological knowledge are fundamental to the economic growth and well being of any modern society. Economic growth today is a combination of capital accumulation and knowledge accumulation. Knowledge also plays a crucial role in resolving social problems related to areas such as health, water supply and conservation, energy generation and utilization, food security and environmental protection.

But knowledge itself, both basic and applied, is being generated very fast and is growing exponentially. More new information has been produced within the last three decades, than in the last five millennia. We should be poised for dramatic scientific advances and break-throughs in the macro-frontiers of the universe on the one hand, and microscopic secrets of the human body on the other hand and everything in between.

But not all generated knowledge is at the sophisticated levels. We should expect similar developments in areas related to everyday life and to marketplace. In fact, all facets of society are becoming knowledge dependent. Moreover, participation in a modern technological world necessitates a significant level of scientific and technological understanding. This applies to all areas of everyday living, including banking, business transactions, health services, transportation vehicles, home appliances, utilities, communication and information exchange.

\section{Unpredictable future}

Science education has to meet the needs of the future. But what is the future? Can we predict the future?

Sometimes we think of the future as a linear expansion of the present and we underestimate it. Here are some examples of past predictions of the future:

- In 1897, the President of the British Royal Society predicted: "Radio has no future."

- In 1899, the US Commission of Patents predicted: "Everything that can be invented has been invented."

- In 1903, a lawyer advising a client not to invest in Ford Motor Company, predicted: "The horse is here to stay, but the automobile is only a novelty - a fad."

- In 1946 the Head of $20^{\text {th }}$ Century Fox predicted : "Television won't be able to hold on to any market it captures after the first six months. People will soon get tired of staring at a plywood box every night." 
- In 1949 Popular Mechanics Magazine predicted: "Computers in the future may... perhaps only weigh 1.5 tons."

- Finally in 1977 President of Digital Equipment Corporation predicted: "There is no reason for any individual to have a computer in their home."

We cannot predict the future. The only thing we can predict is that it will be beyond our wildest imaginations.

\section{IV. "Marketization" of Educational Services}

The relationship between the marketplace, the state and the education sector is evolving significantly. Education is no longer a monopoly of the state or a "protected industry. "Local and transnational private entities have entered this field as a result of expanding economic liberalism, increasing political pluralism and rising demand for education. Government funding has not been able to cope with the evolving demands, and new providers have entered the market in large numbers. In fact, the growth of private tertiary education institutions has been more rapid in developing countries than in industrialized countries. A large number of the new providers are private, non-governmental institutions, many of them being established in partnership with American or European institutions of higher learning, and most are profitdriven and therefore, accessible only to those who can afford them.

Information and Communication Technologies (ICTs) have facilitated this trend. ICTs allow for flow of information and educational services across borders and over geographic and social barriers. Open and virtual universities and high schools as well as internet-based lifelong educational programs have simultaneously internationalized and decentralized education. Education and training can now be practiced by anyone, anywhere.

\section{B. Implications for Science Education}

A cursory analysis of these challenges quickly and immediately points to three crucial implications for science education: target, approach and curriculum:

\section{Target}

To meet the above challenges, it is obvious that every country needs to develop a national scientific and technological capacity - the ability to understand, select, adapt, use and develop new basic and applied science. Here, institutions of higher 
education and training must be first-class to equip individuals with the advanced knowledge and skills required to produce new knowledge through research and to serve as channels for the acquisition, transfer, adaptation and dissemination of knowledge generated elsewhere in the world.

What is not always obvious is the need to enhance science teaching and learning for every citizen at the pre-university levels :

1. College-bound graduates need a solid scientific and technological foundation that compares well with international standards, to serve as preparation for specialization in these fields and for the creation of a cadre of scientists, innovators and managers of transfer of knowledge and technology;

2. Graduates entering the market place need the necessary knowledge and skills to function in the workplace and the tools to access, assess, adopt and apply new knowledge acquired the conventional and advanced means to apply in new jobs;

3. All graduates need the ability to integrate knowledge from different disciplines and apply them to the solution of real-life problems, in a society that is becoming more technologically sophisticated and dependent.

\section{The Approach}

Science and mathematics are supposed to provide conceptual and technological tools that allow people to describe and explain how the world works with power and precision, and to achieve a richer understanding and appreciation of the world they experience.

Unfortunately though, science education, in most cases, has reduced the wonderful, dynamic and multidimensional world of science into flat texts, scripted demonstrations and occasional cookbook experiments. Similarly, the world of mathematical constructs, concepts and relationships has been transformed into drill and practice of computations and abstract problems.

Our understanding of the nature of learning and of the nature of scientific knowledge is leading to enhanced instructional programs in sciences that have the following
three characteristics:

1. Hands-on: Students are actually allowed to perform science (directly and vicariously) as they construct meaning and acquire understanding. It takes these subjects out of the realm of the magical or extraordinary; 
2. Minds on: Activities focus on core concepts, allowing students to develop higher-order thinking processes and skills, and encouraging them to question and seek answers that enhance their knowledge and thereby acquire an understanding of the physical universe in which they live.

3. Reality on: Students are presented with problem-solving activities that incorporate authentic, real-life questions and issues in a format that encourages drawing on multidisciplinary knowledge, collaborative effort, dialogue with informed expert sources, and generalization to broader ideas and application. The objective is to promote students' insight into the real scientific, technological and every-day world, and the skills needed to live and work effectively.

\section{The Curriculum}

The future of society, the workplace and knowledge is changing so dramatically and fast that it poses a nightmare for the curriculum planners. We are educating students for the unknown. What kind of science curriculum should we have? Does the traditional curriculum offer enough flexibility and elasticity?

If the curriculum is a collection of facts, concepts and theories, no matter how well articulated and presented, it may have limited shelf life for the student. There must be more. It seems to me that the best we can do is to equip students with the necessary conceptual, cognitive, attitudinal and social tools to continue learning anytime, anywhere, on demand. The skills include :

1. A conceptual open-ended foundation of the physical, human, environmental and cultural world

2. Skills to access knowledge, assess it, and apply it.

3. Skills to analyze, critique, apply knowledge to generate solutions, and test options.

4. Interpersonal skills to interact and work collaboratively.

\section{The Role of ICTs in Science Education}

The integration of modern information and communication technologies (ICTS) into the teaching/learning process has great potential to entance the tools and environment for learning of science. Research and experience has shown that ICTs, well utilized, enhance the teaching/learning process in a multitude of way. Here we propose five explications: 


\section{Motivating and Engaging Students in Learning}

The famous astronomer Carl Sagan used to say that all children start out as scientists, full of curiosity and questions about the world, but schools eventually destroy their curiosity. Research shows that students are motivated only when the learning activities are authentic, challenging, multidisciplinary and multi-sensorial. Videos, television and computer multimedia software can be excellent instructional aides to engage students sensorial apparatus and bring a sense of enjoyment to the learning process.

\section{Bringing Abstract Concepts to Life}

Teachers have a hard time teaching and students have a hard time learning abstract concepts, particularly when they go against immediate intuition and common knowledge. Images, sounds, movements, animations and simulations may demonstrate an abstract concept in a real manner.

\section{Fostering Inquiry and Exploration}

The inquiry process is a source of affective and intellectual enjoyment. This sense of adventure is taken away in a traditional classroom, where questions and answers are established a priori and are unrelated to students' interests, and where research is reduced cookbook lab exercises. The problem for many institutions and educators is that inquiry and exploration require resources that are unavailable in traditional classrooms, such as large databases and well-equipped laboratories. ICTs have the potential to let students explore the world in cost-effective and safe ways. Videos and computer animations can bring movement to static text book lessons. Using these tools, students can initiate their own inquiry process, develop hypotheses and test them. In a virtual reality setting, students can manipulate parameters, contexts and environments, and can try different scenarios. Moreover, ICTs allow students to utilize the information acquired to solve problems, formulate new problems, and explain the world around them. For instance, computer applications have the potential to store massive amounts of data, plot curves, conduct statistical tests, simulate real life experiments, built mathematical models, and produce reports - all this with speed and accuracy.

One striking example is the virtual lab. All school systems want to provide labs because science is empirical. But few schools have them, fewer have them equipped and fewer yet are willing to risk using them. Technology allows for video and digital Demonstrations as well as digital simulation of lab activities in a very real manner - but without the risks and costs associated with lab experiments. Simulations of science lab experiments could also use real data. Data-logging is a type of soffware that enables the use of actual sensors and probes connected to the computer. 
Rather than feeding the information manually to the computer, the sensor directly uploads the measurement, thus reducing the margin of error, and reproducing a situation that is closer to an actual experiment.

Computer simulations are particularly helpful for learning science in the following situations:

- Experiments that are too risky, expensive or time consuming to be conducted in a school laboratory, such as those involving volatile gases;

- "Tidy" experiments that require precision so that students can see patterns and trends; students may not be able to achieve the necessary precision without simulation tools;

- Experiments that break the laws of nature, such as exploring kinematic collisions that violate conservation of momentum law;

- Experiments where ethical issues are at stake, such as in the case of some biology experiments.

Simulations should not totally replace hands-on activities. They should rather prepare the learner to conduct real-life experiments - in the same manner that flighf simulations prepare the student-pilot for test flying.

\section{Connecting with the World}

ICTs can take students on exciting journeys through time and space. Movies, videos, audio technology, and computer animations bring sound and movement to static textbook lessons and enliven children's reading classes. They also provide social studies and foreign language students with vicarious experiences of distant societies and bygone times. The Internet offers virtual reality settings where students can manipulate parameters, contexts, and scenarios. Videos and computer animations enable students to "witness" a volcano eruption to learn about pressure, rock formation, or psychological and sociological responses to crises. Videos, DVDs, computer software, and the Internet bring to schools anywhere in the world information that can be obtained only through the use of powerful scientific instruments that no single school can afford. For instance, at the Website of the Space Telescope Science Institute, students can observe planets and stars through the lens of the Hubble Space Telescope. At the Molecular Expressions Web site, they can examine tiny insects under fluorescence microscopy or study details of DNA structure. 
More than any other technology, the Internet opens new opportunities for collaborative work. From group discussions to full collaborative research projects, the Internet has the potential to connect classrooms to research centers and students to actual scientists.

\section{Connecting teachers and students}

Technology supplies teachers and students with a platform through which they can communicate with colleagues from distant places, exchange work, develop research and function as if there were no geographical

\section{Conclusion: To "tech" or not to "tech"}

To "tech" or not to "tech" science education is NOT the question. Technology is only a tool: no technology can fix a bad curriculum or compensate for bad teaching. In fact, if we are going in the wrong direction, technology will get us there faster. For instance, if teaching is demonstrating and multimedia programs for this purpose will not have the desired impact. Also, if students are not asked to search and work collaboratively, and if teachers function independently, investment in connectivity will not be cost-effective. The effectiveness of different levels of sophistication of use of ICTs depends to a large extent on the philosophy of science education and on the roles of learners and teachers as practiced in the educational process. Unfortunately, however, much introduction of technology into the educational system comes not from a process of needs identification and analysis but in response to a perceived need to innovate or to pressure from outside groups (parents, vendors, employers). This is not necessarily a bad thing for triggering the process, but cannot be the only reason for investing in ICTs.

\section{The real questions should be}

1. How can we exploit the potential of technologies to make science education more effective and more responsive to present and future challenges?

2. How can ICTs turn science education from learning about science to doing science?

Perhaps one of the best uses of technology is to strengthen the campus/school sefting with better resources, empower the instructor to become a more effective facilitator of learning, and enhance the role of the student as a learner, thinker, investigator and problem-solver. This objective can be achieved by integrating into the course structure on-line technologies, video technologies, and computer 
technologies (including text, graphics, digitized audio and video, and interactive media). If these technologies are packaged into a network, it allows participating institutions to share the best instructors, materials, sottware, strategies and experiences and realize economies of scale in terms of cost, resources and expertise.

One final note: If technology-enhanced programs are taped classrooms, digital texts and Power-point transparencies, then we are missing on the tremendous potential of technologies that can animate, simulate, capture reality, add movement to static concepts, and extend our touch to the whole universe. With imagination and appropriate tools, we can steal the thunder and touch the lightening! 